\title{
Concept Mapping for Higher Order Thinking
}

\author{
http://dx.doi.org/10.3991/ijep.v3iS1.2401 \\ S.M. Zvacek ${ }^{1}$, M.T.Restivo ${ }^{2}$ and M.F. Chouzal ${ }^{2}$ \\ ${ }^{1}$ Fort Hays State University, Hays, KS, USA \\ ${ }^{2}$ Universidade do Porto, Porto, Portugal
}

\begin{abstract}
Engineering education is facing a changing world in which how one thinks is becoming more important than what one thinks; that is, our course content is important but constantly changing and we need to help students learn how to think about that content.
\end{abstract}

Today's students have grown accustomed to immediate rewards, multi-channel stimuli, and rapid-fire communications. As a result, they are often impatient and suffer a lack of focus. When reflection is called for in the learning process - a time consuming practice - students may find it difficult to overcome the conflict between their typically speedy management of priorities and the focused, time-intensive thinking required to acquire a strong foundation of declarative knowledge.

Therefore, the exploration of tools to facilitate the formation of deep knowledge structures is essential. One instructional strategy that shows promise is the use of concept mapping, a learning activity that requires students to explain their understanding of important ideas and the relationships among those ideas. This paper describes a pilot project to integrate concept mapping into a Mechanical Engineering Course and the preliminary results of that project.

This project has been established within the Working Group of "Tools for Developing High Order Thinking Skills", of the Portuguese Society for Engineering Education, in which the first author is the leader and the other two co-authors, are working group members.

Index Terms-Concept maps, Higher Order Thinking, Student Engagement, Teaching and Learning.

\section{INTRODUCTION}

As cognitive processing research advances our understanding of how learning occurs within the brain, educators can take this new knowledge and apply it to teaching. Currently, we know that although our foundational learning involves acquiring basic concepts, deep understanding and higher order thinking rely on the relational links among those topics. Unfortunately, there is ample research to suggest that although engineering students do well memorizing large amounts of information, their ability to use that information for complex problem-solving, critical thinking, or creative activity remains limited [1]. The challenge is to introduce teaching strategies that move student cognition into these realms -- into the domains of higher order thinking skills.

Within the Portuguese Society for Engineering Education (SPEE), a workgroup for Higher Order Thinking Skills has several members working with concept mapping in their courses. This paper discusses how concept maps can be used for instruction and then describes a pilot project to integrate concept maps into a course within the Mechanical Engineering Integrated Master's Degree, the preliminary results of this activity, and recommendations based on these results.

\section{CONCEPT MAPPING AND LEARNING}

Concept maps are visual representations of how we organize knowledge for ourselves and how we tie ideas together into a network of nodes and connecting links in our minds. When students are required to create concept maps that represent their thinking on a subject the relationships among seemingly isolated ideas can become clear. Or, conversely, areas in which they lack important declarative knowledge or where their thinking is confused or inaccurate become obvious allowing the instructor to provide guidance and correction before subsequent learning is confounded. Concept mapping was developed as an instructional tool in the 1970s by Joseph Novak and he continues to conduct research (along with many other professional educators) on its effectiveness in a variety of settings and for multiple types of tasks [2, 3]. Novak was especially interested in the value of concept maps to activate prior knowledge and to enhance the intentional relationships among important ideas, as opposed to the type of rote learning that occurs when concepts are introduced randomly or without clear ties to what the student has already integrated into his or her cognitive frameworks. Novak was strongly influenced by the work of David Ausubel, whose theory of assimilation recognized the importance of context when introducing new ideas [4].

Concept maps have a distinct advantage over many other types of instructional strategies when it comes to supporting higher order thinking skills. Creating a concept map requires a clear understanding of how ideas are related to one another, a cognitive skill that cannot be accomplished simply through memorization or even the use of heuristics. For this reason, assigning students the task of developing a concept map - whether individually or in collaboration with others - can prod them to consider what they have learned in a metacognitive (i.e., thinking about their own thinking) manner [5]. This self-reflective activity promotes deeper learning and stronger retention of new knowledge.

When concept maps are used in an instructional setting it is usually necessary to introduce the strategy to students by demonstrating how to create a map or to work through the process as a group to avoid additional stress or confusion related to the process itself. Instructors might also choose to assign a separate task of identifying and clarifying relationships among ideas prior to beginning a concept mapping exercise to model this behavior on its own.

A simplified explanation of how to create a concept map includes the following steps: 


\section{CONCEPT MAPPING FOR HIGHER ORDER THINKING}

1. Identify the central topic or question;

2. Brainstorm a list of ideas that includes as many concepts as possible that are related (directly or indirectly) to the central topic;

3. Organize the concepts by grouping them in an arrangement appropriate to the topic, for example, specific-to-abstract or categorized by sub-topic; and

4. Connect the concepts with lines that specify the type of relationship between the ideas (for example, "Concept A leads to Concept B" or "Concept C is a subset of Concept D.”) The identification of relationships - and the cross-linking that may occur - is typically the most challenging element of this activity for students, initially. Fig. 1 is an example of a simple concept map that includes the linking relationships.

Creating these links (i.e., propositions) frequently requires analytical skills, synthesizing seemingly-unrelated ideas, interpreting phenomena or trends, and examining characteristics and patterns of behavior based on a systems view of a particular environment. Cross-links, the ties that are identified between concepts in not-obviouslyrelated areas of a concept map, help students develop a big-picture understanding of how the new ideas can be integrated into familiar structures and retrieved more effectively for use in new situations.

Although concept maps were initially used with children to represent their understanding of scientific knowledge as a way to compensate for their inability to explain precisely how they were organizing key ideas, this strategy has also been adopted to represent "expert knowledge.” Many experts have such sophisticated knowledge structures they have developed over time that articulating the nuances of such learning can be exceedingly difficult. Concept maps, in these cases, can be created through the use of careful interviewing, incident analysis, and problem-solving exercises as a way to capture tacit knowledge not readily apparent to a novice in the field.

Eventually, students should be able to create their own maps as a way to organize their study notes or outline a research paper. Concept maps can also be used as an assessment activity to evaluate learner understanding and identify misconceptions, enabling the instructor to give specific feedback customized to each student's difficulties. Concept mapping as an organizational or instructional strategy can be adapted to a wide variety of purposes.

\section{AN INTERNATIONAL COLLABORATION}

The present work is an example of cross-disciplinary collaboration between postsecondary educators from the US and Portugal. In June 2011, the first author offered a structured week-long course of two ECTS in collaboration with the second author (at the time, the president of the Portuguese Society for Engineering Education - SPEE). This workshop series was supported by the SPEE, the University of Porto (UP) and by its Faculty of Engineering (FEUP).

The course began with an introductory workshop entitled "Tools to Develop Higher Order Thinking Skills" and was opened to the UP and SPEE communities, in addition to the IEEE Education Society Portuguese Chapter. This initial workshop included discussions and group activities on metacognition, problem-solving, and self-regulated learning, as well as techniques for teaching these skills. Professors from several different Portuguese universities and a variety of disciplinary areas attended the workshop, sharing ideas, learning new teaching strategies, and engaging in thoughtful conversations.

On the following days, four highly-focused workshops of three-and-a-half-hours each were provided for a limited number of engineering teachers (each held to a maximum of 25 participants) from several higher education institutions of northern Portugal, following the mission of SPEE. These workshops were more intensive than the introductory session and delved into the topics of Concept Maps, Self-Regulated Learning, Problem-Solving Skills, and Strategies for Teaching Higher Order Thinking. They were specifically designed to expose faculty members to new teaching strategies, and to enable them to develop one or more lessons using their own course materials.

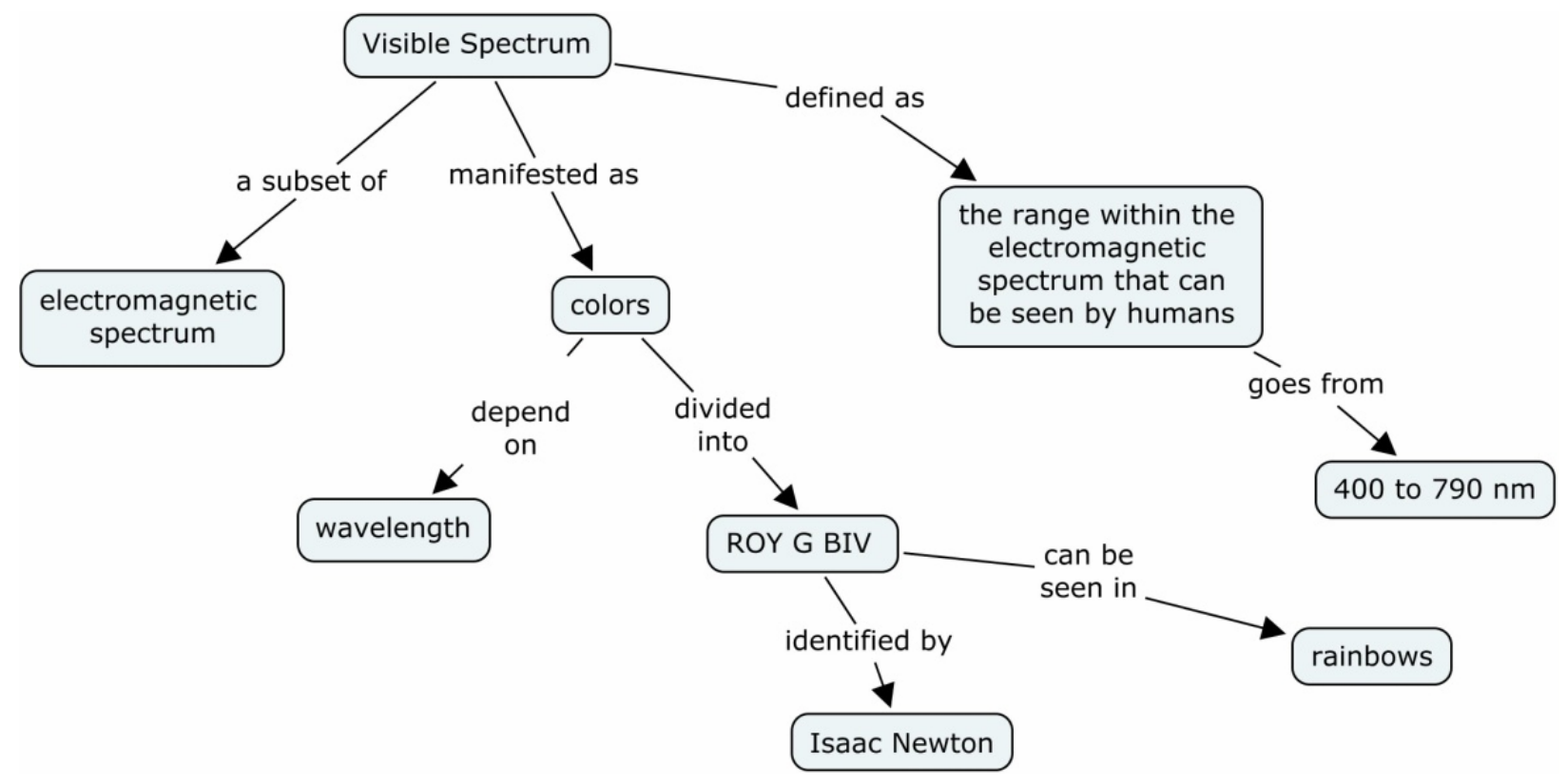

Figure 1. An Example of a Simple Concept Map 
The content of the Concept Maps workshop is explained in detail in this work. The remaining workshops are summarized below:

Student Self-Regulation - Many students begin higher education without the self-regulation skills that will help them to be academically successful. Instructors can help their students develop these skills, such as time management, self-assessment, note-taking, and similar routines. Although some students learn such strategies on their own, we can provide guidance for others to adopt these techniques that can improve the learning and make better use of their study time.

Developing Problem-Solving Skills - Our students need skills to solve problems independently with only minimal guidance, but much of our instruction in higher education presents well-defined issues with easily-identified solution paths. In the real world, problems are vague, complicated by irrelevant information, and may have many possible solutions. This work session concentrated on developing activities to help students learn more about understanding and solving different types of problems.

Strategies for Teaching Higher Order Thinking - This work session included several different strategies that participants can work with to help students develop skills of analysis, inference, creativity, synthesis, and others. For example, the use of peer teaching has been shown to increase deep understanding of concepts, so participants had the opportunity to create a lesson integrating this technique. Another option was to enhance students' ability to draw conclusions from data, or to develop their ability to identify errors in seemingly accurate course content.

A direct consequence of this week-course was the inauguration of a new SPEE Working Group: "Tools for Developing High Order Thinking Skills", in which the first author is leader. The present work is a result from this group activity, in which the other two co-authors are group members.

This article describes the result of using Concept Maps within a course of an integrated master in the Mechanical Engineering Department at FEUP, in which the second author is responsible and the third is heavily involved in the lab sessions.

\section{ELECTRONIC AND INSTRUMENTATION COURSE CONTENT AND STRUCTURE}

Students who participated in this project were enrolled in "Electronics and Instrumentation", the main course incorporating a hands-on component on measurement principles, methodologies, and uncertainties, offered the first semester of their fourth year. In this course, around $60 \%$ of the time ( 2.5 hours per week) is devoted to laboratory activity involving roughly 160 students. In the lab, students are supposed to have confirmatory practices of the laws, effects, and characteristics of many measuring devices associated with typical signal conditioning circuits. They are also expected to gain familiarity with laboratory and/or industrial equipment as well as measurement procedures and methodologies, covering an extensive range of physical quantities and metrology concepts of interest in the mechanical engineering field. There are also theoretical lecture sessions of 1.5 hours per week during which theoretical principles and concepts supporting that week's laboratory activities are explained.
Complementing the main goals referred to above, the course is also intended to promote student teamwork skills, personal responsibility, and criticism through the preparation of lab activities, short lab discussions and reports, and exercises requiring self-organizing, conflictsolving capabilities, and, if possible, implementing some practice in learning-through-teaching.

Theoretical sessions are planned to make concepts and principles of the theoretical syllabus understandable and to discuss and analyze some typical problems. There may also be simple demonstrations, video clips, simulations, and animations to support discussion of constructive solutions and their main characteristics. A Moodle elearning course is provided as a repository of content (self-contained thematic courses, thematic slideshows, online labs, problems, and multimedia). An e-book is provided with the theoretical content for the lab tasks and their guiding procedures with complementary multimedia contents (clips, animations, and simulations) [6]. Synthesis and open questions for evaluation of the acquired knowledge are also available.

In the lab sessions students were organized into four work groups. The main experimental tasks focused on confirming the working principles of sensors/transducers, determining their characteristics and associated measured parameters (sensitivity, resolution, linearity, stability, hysteresis, etc), and comparisons with data provided by the manufacturers. Some calibration procedures are made within experimental constraints, allowing students to get real experience with equipment usability and its limitations. The use of data acquisition systems is an early practice. With several tasks, students must face the concept of measurement uncertainty, typically not an easilygrasped idea at this point. The lab activities are intended for manipulating equipment and devices used for experimental tasks, developing skills of analysis, interpretation, criticism, and reporting their experimental results. Additionally, the goal of helping students become active learners requires them to engage in soft skills such as decision-making, planning, conflict resolution, and group presentation.

\section{Problem And Intervention}

Although the students in this course are able to memorize large amounts of content, they have difficulty relating the topics from their theoretical lectures to what they are doing in the lab; that is, they are unable to explain "why" things are happening the way they are in the lab activities. This has become evident in their responses to theoretical questions in exams and when asked in lab exams to explain their results.

Therefore, the integration of concept mapping was proposed for this course with the goal to further the students' awareness of their own thinking and how they organize knowledge for themselves. Such metacognitive activity reinforces the kind of abstract reasoning that is desirable but had not been exhibited by students in previous semesters.

Concept mapping was introduced in both the theoretical lectures and in the lab classes. During a few of the lectures throughout the semester, the instructor built concept maps with student input, Fig. 2. Students were given Post-it notes to generate the concepts and guidance on how to organize their ideas and correlate those ideas between the 


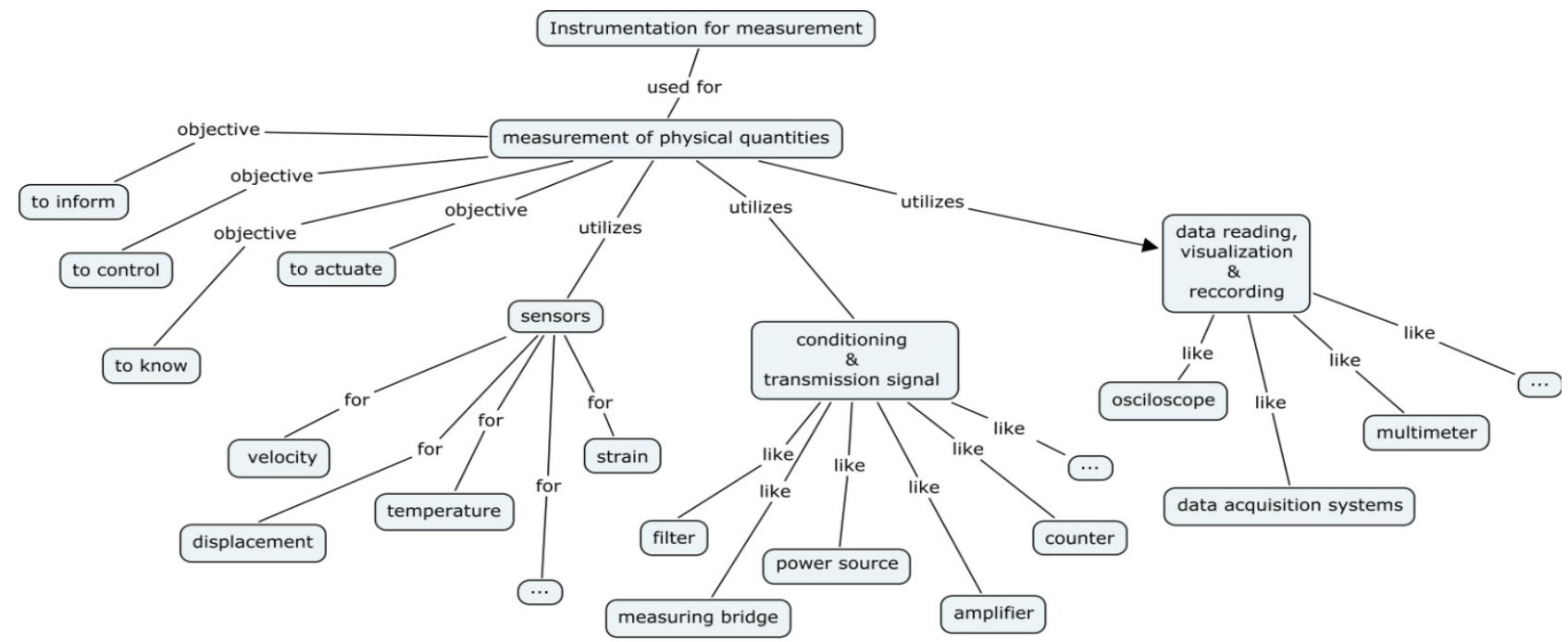

Figure 2. Concept Map Created with Student Input (Theoretical Lecture)

lecture and lab activities. In addition, students were encouraged to create concept maps on their own, although there was limited interest in this activity and the lecture hall environment plus the group size (approximately 150 students) posed significant obstacles to the success of such an activity. For approximately 100 students (of the 150 in the course), this was the only exposure to concept mapping within the course.

There were around 16 students enrolled in each lab class section. Three of the nine lab class sections (approximately 48 students, total) were given the option to write a text-based was more enthusiasm for the concept mapping exercise in this environment than in the lecture setting, probably related (at least initially) to the novelty of a new type of assignment, and possibly the desire among some students to avoid a writing assignment. The concept maps were created at the end of the lab session, collected for review by the instructors, and later were returned to students with corrections. These activities (concept mapping or writing a narrative) occurred every week during the term. Anecdotal evidence (i.e., instructor observation) indicated that students quickly grasped the principles of concept mapping and became adept at creating them by drawing freehand or using software freely available online, such as FreeMind or C-Map. A map developed by students as part of their lab activity is shown in Fig. 3.

\section{RESULTS}

Although this was a pilot project and not expected to generate significant changes in the students' academic achievement, some interesting preliminary results emerged that the instructors considered encouraging. For example, there were positive correlations between the use of concept maps and exam scores as well as overall positive survey responses from students on the value of concept mapping for learning. The less-positive results (based on the initial reasons for using concept maps) generated ideas for revising the use of concept maps for both lecture sessions and lab classes in upcoming semesters.

Students who used concept maps in their homework and lab sessions (sample A) scored more highly on almost all measures of the final grading scale than those who were exposed to concept mapping only in few theoretical lectures (sample B), (Table 1).

TABLE I.

MEAN SCORE VALUES OF ALl AsSESSMENTS

\begin{tabular}{|l|c|c|c|}
\cline { 2 - 4 } \multicolumn{1}{c|}{} & \multicolumn{3}{c|}{ Assessment mean values and \% deviation } \\
\hline $\begin{array}{l}\text { Assessment } \\
\text { components }\end{array}$ & $\begin{array}{c}\text { Students A } \\
\text { (meanvalue) }\end{array}$ & $\begin{array}{c}\text { Students B } \\
\text { (meanvalue) }\end{array}$ & $\begin{array}{c}\mathbf{1 0 0 * ( A B ) / ( ( A + B ) / 2 )} \\
\text { \% }\end{array}$ \\
\hline $\begin{array}{l}\text { Multiple- } \\
\text { choice queries } \\
\text { beginning lab } \\
\text { classes }\end{array}$ & 15 & 12.4 & $+19 \%$ \\
\hline $\begin{array}{l}\text { Lab Perform- } \\
\text { ance }\end{array}$ & 13.6 & 13.6 & 0 \\
\hline $\begin{array}{l}\text { Final Lab } \\
\text { Synthesis }\end{array}$ & 12.7 & 11.7 & $+8.2 \%$ \\
\hline $\begin{array}{l}\text { Continuous } \\
\text { Assessment }\end{array}$ & 13.6 & 12.9 & $+5.3 \%$ \\
\hline Lab Exam & 12.4 & 10.3 & $+18.5 \%$ \\
\hline Written Exam & 11.3 & 9.7 & $+15.2 \%$ \\
\hline Final Score & 12.4 & 10.9 & $+12.9 \%$ \\
\hline
\end{tabular}

Although these results cannot be interpreted to mean that the introduction of concept mapping was solely responsible for the higher scores it provides encouragement to continue using them.

In a survey distributed at the end of the fall term, students were asked about their use of concept maps and how valuable this instructional strategy had been for them. Although the rate of response was low, the answers were encouraging. For example, in response to the question, "How did you use concept maps?" the two most frequently chosen responses were "To help me remember important ideas" and "To help organize my ideas.” When asked, "Did using concept maps help you to see where your understanding was incomplete or inaccurate?” 38\% of the students responded with, "Yes, definitely." Even more encouraging was that $44 \%$ replied with "Yes, definitely" to the question, "Concept maps can help us explain our thinking to others. Did you feel that this was true for you?" Considering that this was a brand-new technique for the learners that required more effort to complete than previous activities, these positive responses are especially encouraging. 


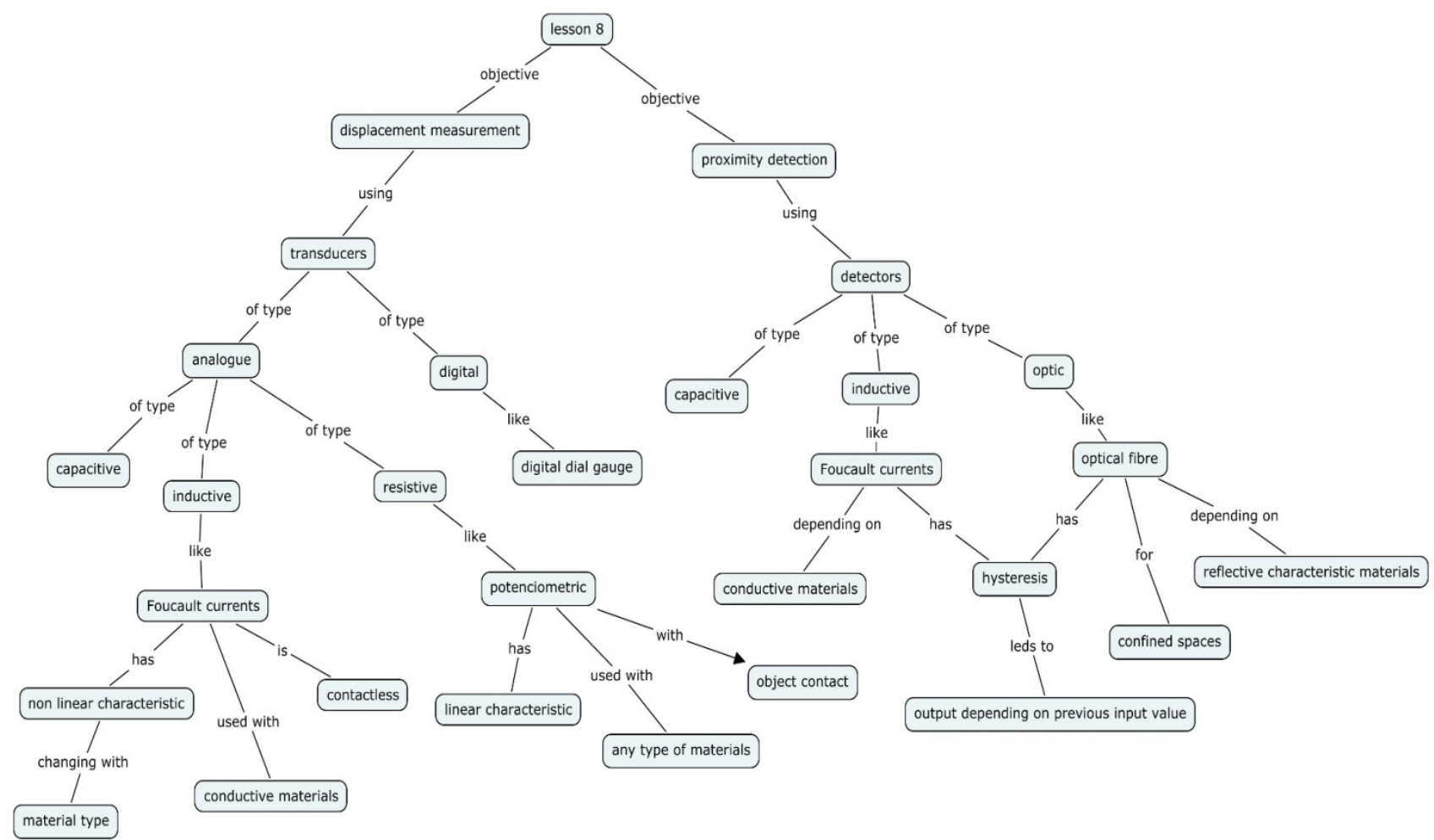

Figure 3. Student-Created Concept Map (Lab)

\section{FUTURE PLANS}

In future semesters, the use of concept mapping will be revised and refined to be more closely aligned to course objectives. Other changes may involve how concept maps are introduced to students, how frequently they are used, and/or at what point in the lab activities the concept maps will be generated. For example, concept map development as part of a pre-teaching activity might help students to understand what they bring to the course in terms of existing knowledge and how they might build on it, as well as misconceptions that could interfere with further understanding.

To assist with data gathering, a scoring system or rubric will be developed to review student-created concept maps in a consistent manner. Criteria will include the quantity and quality of nodes and links generated, for example. As an exploratory learning activity, this project shows sufficiently interesting potential to continue.

\section{ACKNOWLEDGMENT}

This work is part of a presentation within "Talking about Teaching 2012" Special Track of the Portuguese Society for Engineering Education in the IGIP Annual Conference 2012. The authors wish to thank to Societies, SPEE and IGIP, for their support.

\section{REFERENCES}

[1] C.J. Atman, S.D. Sheppard, J. Turns, R.S. Adams, L.N. Fleming, R. Stevens, D. Lund. Enabling Engineering Student Success: The Final Report for the Center for the Advancement of Engineering Education. University of Washington, 2010. Retrieved from http://www.engr.washington.edu/caee/CAEE\%20final\%20report\% 2020100909.pdf
[2] A.J. Cañas, J.D. Novak, "Re-examining the foundations for effective use of concept maps.”, Second Int. Conference on Concept Mapping (Canas and Novak, eds.) San Jose, Costa Rica, 2006. Retrieved from http://cmc.ihmc.us/cmc2006Papers/cmc2006-p247.pdf

[3] L.H. Jamieson, J.R. Lohmann, Creating a culture for scholarly and systematic innovation in engineering education. Washington, DC: American Society for Engineering Education, 2006. Retrieved from http://www.asee.org/about-us/the-organization/advisorycommittees/CCSSIE

[4] Ausubel, D.P. Educational Psychology: A Cognitive View. New York, Rinehart and Winston, 1968.

[5] J. Turns, C. Atman, R. Adams, “Concept maps for engineering education: A cognitively motivated tool supporting varied assessment functions”, IEEE Transactions on Education, vol. 2, pp. 164173, 2000. http://dx.doi.org/10.1109/13.848069

[6] M.T. Restivo, F. G. de Almeida, M. F. Chouzal, J. G. Mendes, and A. M. Lopes, Handbook of Laboratory Measurements and Instrumentation,” International Frequency Sensor Association (IFSA) Publishing, Barcelona, SPAIN, May 2011.

\section{AUTHORS}

S.M. Zvacek is with the Center for Teaching Excellence and Learning Technologies, Fort Hays State University Hays, KS, USA (e-mail: smzvacek@fhsu.edu).

M.T. Restivo is with Universidade do Porto, Faculdade de Engenharia and with UISPA research Unit at IDMECPólo FEUP, Porto, Portugal (e-mail: trestivo@fe.up.pt).

M.F. Chouzal is with Universidade do Porto, Faculdade de Engenharia and with UISPA research Unit at IDMEC-Pólo FEUP, Porto, Portugal (e-mail: fchouzal@fe.up.pt).

This article is an extended and modified version of a paper presented at the IGIP2012 conference, held 26 - 28 September 2012, in Villach, Austria. Received 30 November 2012. Published as resubmitted by the authors 28 January 2013. 